\title{
Innovation Management to Sustain Competitive Advantage: A Qualitative Multi-Case Study
}

\author{
Ghayth Tahat (Corresponding Author) \\ Capella University \\ Georgia, USA \\ Tel: 8433274752 \\ E-mail: Engtahat@hotmail.com
}

Received: April 2, $2021 \quad$ Accepted: April 26, $2021 \quad$ Published: June 1, 2021

doi:10.5296/rbm.v8i1.18799 URL: http://dx.doi.org/10.5296/rbm.v8i1.18799

\begin{abstract}
The importance of new product development (NPD) and innovative capabilities in marketing, innovation, and business strategy has been recognized by management and researchers. Knowledge management and organizational capabilities have also been explored and evaluated by researchers and practitioners. However, the current literature shows a lack of connection between NPD, innovative capabilities, integrated shared knowledge, and organizational capabilities. Also, there is limited knowledge on the impact and the contribution of the integrated shared knowledge and the organizational capabilities to the firm's success, performance, and sustainability. This study aimed to determine if there is a link between NPD and innovative capabilities, integrated shared knowledge, and the organization's capability. The purpose of the research is to explore how shared knowledge and the organization's capabilities influence and contribute to NPD, innovative capabilities, and innovative management. A qualitative, multi-site case study through one-on-one, in-depth interviews with primary decision-makers from technology and innovative companies located in Texas State in the USA is employed. The primary research question that guided the project is: How do shared knowledge and the organizational capabilities that influence NPD and innovative capability contribute to the firm's success, performance, and sustainability? Respondent interviews have been imported and analyzed through NVivo qualitative data analytics software. Findings have been determined using NVivo 11 through theme analysis. A key finding is that shared knowledge and the organization's capabilities are linked and critical for NPD's success and innovative capabilities. A set of recommendations for future researchers is proposed.
\end{abstract}

Keywords: Innovation Management, Sustainability, Competitive Advantage, Qualitative Study, Multi-case Study

\section{Introduction}

The importance of new product development decisions in business strategy has been 
recognized by strategy researchers and business leaders (Lin \& Chen, 2008). There is a substantial amount of research regarding NPD and innovative capability and its effects on the firm's sustainable competitive advantage (Ernst, 2002; Zhang, 2012). Existing literature ignores the role and the impact of shared knowledge and the organization's capabilities on NPD and innovative capabilities and their contribution to the firm's success, performance, and sustainability (Lin \& Chen, 2008). Current literature fails to address the influence of shared knowledge and the organization's capabilities on managerial innovation-decision and strategic planning related to NPD and innovative capabilities (Kahn, Barczak, \& Moss, 2006, 2012; Vinayak \& Kodali, 2014). To determine the role of shared knowledge and the organization's capabilities on NPD and innovative capabilities, the researcher has conducted a multi-site case study that involved interviewing primary decision-makers from technology and innovative companies located in Texas (TX).

Innovation has a profound influence on organizational performance, survivability, and several strategic advantages such as eliminating cost, reducing risk, differentiation in new products or services, and increasing quality (Yeşil, Koska, \& Büyükbeşe, 2013). Lawson and Samson (2001) stated that "innovation is a firm's source of new products, processes, and systems for adapting to a changing market" (p. 381). Innovation has been a determinant of survival for any organization; consequently, continuous innovation is instrumental in sustaining competitive advantage in dynamic markets (Xu, Houssin, Caillaud, \& Gardoni, 2010). Innovation is the driving force behind introducing new products, processes, or markets that spawn modern economies and generate new wealth (Xu et al., 2010). Smithies (n.d.) stated in addressing the relation between economics with innovation, which agrees with Schumpeter's (2002) interpretation of economics and innovation, believed the success of the business performance and value creation depends on an organization's robust innovation process. The advancement of technology and communication and the increasing level of global competition caused industries and manufacturers to emphasize innovation and new products (Xu et al., 2010).

Also, innovation is a primary method that ensures sustainable competitive and corporate economic viability (Moustaghfir \& Schiuma, 2013). Developing new products or improving existing products by adding new values is the spirit of innovation and manufacturing companies (Moustaghfir \& Schiuma, 2013). Innovation enables companies to gain a competitive advantage and sustain the firm's core competence and market share (Moustaghfir \& Schiuma, 2013). Apart from that, competitive advantage is derived from the effective use of innovative ideas through new product development (NPD) and innovation implementation.

\section{Problem of the Study}

Organizations recognize and are aware of the essential factors and the critical role of innovation to growth, competitiveness, and the contribution of new product development (NPD) in developing and sustaining the core competencies for long-term competitive advantage and success (Liu, Wang, Yuan, \& Li, 2012). Yang and Yu (2012) stated that the "NPD process can be viewed as a series of activities, including idea generation, product development, and product commercialization" (p. 220). Ngamkroeckjoti, Speece, and Dimmitt (2005) provided a basic definition for NPD as "a process of creating and launching products. From identifying the business needs to its commercialization" (p. 29). Companies can fulfill new customer needs, 
capture new markets, and extend their prominence in a competitive environment through developing new products or enhancing the existing products (Cheung, 2015). Innovation is recognized as an engine for economic growth (Singh \& Bhangoo, 2014) and is cited as an essential valuable element for sustaining competitive advantage (Malewicki \& Sivakumar, 2004). Innovation consistently contributes to NPD (Cooper \& Kleinschmidt, 2010) and is the foundation of new product development (Phillips, 2016).

Innovative and manufacturing companies are concerned with being more proactive and adaptive by developing new values, products, or services and innovative capability faster to satisfy consumers' demands. New technologies, globalization, and dealing with the organizations' issues are some of the issues that develop competitiveness and create competitive advantage (Badrinarayanan \& Arnett, 2014). NPD and innovative capabilities seek to achieve, maintain, and sustain competitive advantage (Liker \& Morgan, 2011). NPD and innovative capabilities need to be continuously assessed and improved. The objective of innovation, particularly NPD, is to provide the manufacturing and innovative organization with the leverage or the advantage of market innovation that supports the business plan with minimum risk (Ismail \& Yusof, 2010). NPD's success is linked to the firm's innovative capability (Lawson \& Samson, 2001). Innovative capability consists of an organization's intangible property and the ability to exploit this property so that the organization can produce innovations perpetually (Saunila \& Ukko, 2013). Lawson and Samson (2001) defined innovative capability as "the ability to continuously transform knowledge and ideas into new products, processes, and systems for the benefit of the firm and its stakeholders" (p. 389).

The extant literature indicates that NPD and innovative capability are central factors to the firm's performance, survival, economic growth, and competitive advantage (Ismail \& Yusof, 2010). Innovation and increased NPD capabilities have become a significant concern for all companies that seek growth and prosperity (Yang \& Yu, 2012). NPD and innovative capabilities help firms differentiate themselves (Zhang \& Zhu, 2015) and enhance their advantage (Yang \& Yu, 2012). The presence of NPD and innovative capability had become significant elements of advanced competitive strategies among manufacturing and innovative companies (Narkhede, 2017).

The critical role and advantages of embracing NPD caused innovative and manufacturing organizations to consider NPD to be a part of its strategies and maintain a competitive advantage (Vinayak \& Kodali, 2014 deemed an essential area in developing and contributing to the firm's competitive advantages (Alvarez \& Iske, 2015; Brunswicker \& Vanhaverbeke, 2014). NPD is also an essential process to attain the firm's objectives, success, strategic planning, training development, sustainable competitive advantage, and organizational renewal in fast-paced or competitive markets (Kang \& Kim, 2010). Lin and Chen (2008) find in their research on NPD's success factors and innovation). NPD is a capability that a firm's innovation capability is developed through two perspectives. The two perspectives appear to have stimulated managers and scholars to understand innovation capability and NPD. The two perspectives are the behavioral aspect of the innovative organization and the organization's willingness to adapt to the required changes (Hussein \& Mourad, 2014; Lin \& Chen, 2008).

NPD and innovation capability enable the organization to integrate and reconfigure 
competence toward achieving goals and addressing the changing environment (Anders, 2006; Dangol \& Kos, 2014; Teece, Pisano, \& Shuen, 1997, 2003). The importance of NPD and innovative capability has led scholars to investigate new product success to better understand the factors essential for NPD and innovation capability (Awwad \& Akroush, 2016). In this regard, Barclay, Dann, and Holroyd (2000, p. 59) suggested that NPD is a "tailored process"; "a company's development environment is unique to that company," therefore, as NPD processes must be "tailored" to suit the specific circumstances. Successful NPD and the implementation of innovative capabilities are crucial for firms across the industries. However, the development of successful NPD and innovative capabilities remains difficult and challenging. Nearly 50\% of new products introduced each year fail (Awwad \& Akroush, 2016). The success or failure rates caused organizations to be adaptive, proactive, and improve processes and products (Awwad \& Akroush, 2016).

Researchers identified and discussed the various factors comprehensively, affecting and contributing to the success of NPD and innovation capability in any firm (Barclay et al., 2000; Lin \& Chen, 2008), which are consistent with Cooper's (2005), Cooper's, Edgett's, and Kleinschmidt's (2007), Cooper's and Schindler's (2008) model, and Yodhia's (2010) factors. The common factors in NPD success across highly productive and best performers in NPD were revealed in the American Productivity and Quality Centre (APQC) study. NPD's common success factors are product innovation, technology strategy, resource commitment, effective and flexible implementation system, and the right climate for innovation, true cross-functionalteams, and management commitment (Ismail et al., 2012). Against this, the problem of the study is to determine if there is a link between NPD and innovative capabilities, integrated shared knowledge, and the organization's capability, as well as explore how shared knowledge and the organization's capabilities influence and contribute to NPD, innovative capabilities, and innovative management.

\section{Questions of the Study}

Due to the nature of the study, the following main and sub-questions are articulated.

1. How do shared knowledge and the organization's capabilities affecting NPD and innovative capability contribute to the firm's success, performance, and sustainability?

Sub-questions were needed to be addressed to support the fundamental questions. The research sub-questions are:

a. What is the importance of shared knowledge and the organization's capabilities regarding their effect on product innovations and the firm's performance?

b. What are the benefits of shared knowledge and the organization's capabilities to the firm's success and performance?

c. How do shared knowledge and the organization's capabilities contribute to the organization's strategic planning and objectives?

Answering the central and the sub-questions helps to enhance, provide a better understanding of how shared knowledge and the organization's capabilities contribute to the firm's success, 
performance, and sustainability, and reveal the essential role and connection of the shared knowledge and the organization's capabilities to NPD and innovation capabilities.

\section{Objectives of the Study}

The following objective is formulated to answer the question of the study.

1. Explore the contribution of the shared knowledge and the organization's capabilities affecting NPD and innovative capability to develop the firm's success, performance, and sustainability.

2. Examine the importance of shared knowledge and the organization's capabilities regarding their effect on product innovations and the firm's performance.

3. Identify the benefits of shared knowledge and the organization's capabilities to the firm's success and performance.

4. Study the contribution of the shared knowledge and the organization's capabilities to develop the organization's strategic planning and objectives.

\section{Significance of the Study}

The significance of this study is highlighted by the importance of shared knowledge and the organization's capabilities affecting NPD and innovative capability contribute to the firm's success, performance, and sustainability. NPD and innovative capabilities for many firms are a potential source of competitive advantage in evolving markets (Li, Zheng, \& Wang, 2016). There is a substantial amount of research regarding factors that affect NPD and innovative capability and their effects on the firm's sustainable competitive advantage. The relationship between NPD and innovation capability has been tested in the literature (Ernst, 2002; Kahn et al., 2012; Vinayak \& Kodali, 2014; Zhang, 2012). Even though researchers and practitioners contended to explore the success and the affecting factors of NPD and organizational capabilities, more insights are required to manifest the paradigm.

Existing literature ignores the role and the impact of shared knowledge and the organization's capabilities on NPD and innovative capabilities and their contribution to the firm's success, performance, and sustainability. The existing literature fails to address shared knowledge and the organization's capabilities on managerial innovation-decision and strategic planning related to NPD and innovative capabilities. This multi-site case study explores how shared knowledge and the organization's capabilities contribute to the firm's success, performance, and sustainability and examines the connection and the critical role of shared knowledge and organizational capabilities that affect NPD and innovation capabilities. By answering the research questions, the study enhances how shared knowledge and the organization's capabilities, the impact of NPD, and innovative capabilities contribute to the firm's success, performance, and sustainability.

Hopefully, the findings reveal new insights and perspectives relevant to understanding how shared knowledge contributes to NPD's success and innovative capability and the firm's performance and sustainability. The findings may also yield important managerial implications and assist in the decision-making process regarding sustainable competitive advantage. 
Identifying how shared knowledge and the organization's capabilities contribute to the firm's success, performance, and sustainability may help managers understand what makes a firm more efficient and well-organized in NPD and innovative capabilities activities and processes. The new insight is necessary for managers who aim to increase success, performance and maintain the firm's competitive advantage. The results may also contribute to the existing literature on NPD and innovative capabilities by diminishing the gap between theory and practice.

This multi-site case study is also significant to innovation management by providing organizations with a better understanding of the factors deemed critical to the success of NPD and innovative capability, which aid organizations with strategic planning and decision-making about NPD and innovation capability. Increasing awareness of these factors provides organizations with a foundation for exploring their support or development of NPD and innovative capability that contribute to the firm's success, performance, and sustainability.

Importantly, the findings may assist innovative management, practitioners, academics, and researchers in answering, developing, or identifying questions related to research purposes. More importantly, the findings may also help develop a comprehensive understanding of the contribution and impact of the shared knowledge and the organizational capabilities to the firm's success, performance, and sustainability, assisting the firm in developing new practices, programs, decisions, and better strategic plans.

\section{Previous Studies}

Several studies are done on the shared knowledge and the organization's capabilities affecting NPD and innovative capability. Lin and Chen (2008) have found in their research on NPD's success factors and innovative capabilities that a firm's innovation capability is developed through two perspectives. The two perspectives appear to have stimulated managers and scholars to understand innovation capability and NPD. The two perspectives are the behavioral aspect of the innovative organization and the organization's willingness to adapt to the required changes (Hussein \& Mourad, 2014; Lin \& Chen, 2008).

NPD and innovation capability enable the organization to integrate and reconfigure competence toward achieving goals and addressing the changing environment (Anders, 2006; Dangol \& Kos, 2014; Teece, Pisano, \& Shuen, 1997, 2003). The importance of NPD and innovative capability has led scholars to investigate new product success to better understand the factors essential for NPD and innovation capability (Awwad \& Akroush, 2016). In this regard, Barclay, Dann, and Holroyd (2000, p. 59) suggested that NPD is a "tailored process"; "a company's development environment is unique to that company," therefore, as NPD processes must be "tailored" to suit the specific circumstances. Successful NPD and the implementation of innovative capabilities are crucial for firms across the industries. However, the development of successful NPD and innovative capabilities remains difficult and challenging. Nearly 50\% of new products introduced each year fail (Awwad \& Akroush, 2016). The success or failure rates caused organizations to be adaptive, proactive, and improve processes and products (Awwad \& Akroush, 2016). 


\section{Macrothink MInstitute}

Researchers identified and discussed the various factors comprehensively, affecting and contributing to the success of NPD and innovation capability in any firm (Barclay et al., 2000; Lin \& Chen, 2008), which are consistent with Cooper's (2005), Cooper's, Edgett's, and Kleinschmidt's (2007), Cooper's and Schindler's (2008) model, and Yodhia's (2010) factors. The common factors in NPD success across highly productive and best performers in NPD were revealed in the American Productivity and Quality Centre (APQC) study. NPD's common success factors are product innovation, technology strategy, resource commitment, effective and flexible implementation system, and the right climate for innovation, true cross-functionalteams, and management commitment (Ismail et al., 2012).

Despite identifying the success factors that contribute to the success of NPD and innovative capabilities implementation, innovative and manufacturing organizations still encounter a high rate of failure (Zaidi \& Othman, 2014). The failure causes have been summarized by the low execution quality and lack of focus and communications (Kleinschmidt, 1991; Lin \& Chen, 2008). With that, researchers and practitioners are exploring other factors that impact NPD's success and the innovative capability implementation to sustain existing competitive advantage, attain the strategic plans, achieve the firm's goals, and have better performance and productivity (Lin \& Chen, 2008).

Innovative and manufacturing organizations need to be proactive and rapidly active to respond to the dynamic environment and the changes in the consumers' trends. Time and the scarcity of resources are the main obstacles to attain those features, where companies acquire knowledge from outside sources that are useful based on the firm's organizational capability (Eisenhardt \& Martin, 2000). Lin and Chen (2008) recommended investigating the relationship between knowledge management and the integration of shared knowledge of customers, suppliers, and internal capabilities and new product development to examine the impact of applying and exploiting the acquired knowledge from external resources. The recommendations were based on exploring other factors that impact NPD's success and the innovative capability implementation to sustain existing competitive advantage, achieve the firm's goals, and have better performance and productivity (Lin \& Chen, 2008). Another recommendation was to explore the role of shared knowledge and organizational capabilities on the firm's success, performance, and sustainability and examine how shared knowledge and organizational capabilities contribute to NPD, innovative capability, and innovative management.

Innovative firms are aware of the essential role of shared knowledge in developing and sustaining a competitive advantage (Lin \& Chen, 2008). Firms apply a shared knowledge base as a resource capability that facilitates the collaboration and cooperation between the entire members and departments (Lin \& Chen, 2008). Hong, Doll, Nahm, and Li (2004) have addressed three types of knowledge sharing that firms must consider, utilize, and implement in their strategic and training planning. The three types of knowledge sharing, according to Hong, Doll, Nahm, and Li (2004), that regarded as the foundation of knowledge sharing are "shared knowledge of internal capabilities, shared knowledge of customers, and shared knowledge of suppliers (p. 105)." However, the roles of shared knowledge have never been addressed in innovative practice and product development (Lin \& Chen, 2008).

There is limited knowledge on the impact and the contribution of the integrated shared 


\section{Macrothink MInstitute}

knowledge and the organizational capabilities to the firm's success, performance, and sustainability. The extant gap is how the integrated shared knowledge and the organization's capabilities contribute, link, and impact the firm's success, performance, and sustainability (Lin \& Chen, 2008; Vinayak \& Kodali, 2014). The current literature did not address the role and the impact of shared knowledge and the organization's capabilities on NPD and innovation capabilities and their contribution to the firm's success, performance, and sustainability (Yang $\& \mathrm{Yu}, 2012)$. The existing literature has failed to address the influence of shared knowledge and the organization's capabilities on managerial innovation-decision and strategic planning related to NPD and innovative capabilities. Also, the role of shared knowledge that affects NPD and the firm's innovative capabilities had never been examined (Lilleoere \& Hansen, 2011), nor had it been linked to achieve the firm's success, performance and sustain the competitive advantage (Zhang \& Zhu, 2015). There is also information relevant to NPD and innovative capability that would benefit from further research (Brunswicker \& Vanhaverbeke, 2014; Kalluri \& Kodali, 2014).

There is also a gap in how shared knowledge and the organization's capabilities contribute to the firm's success, performance, and sustainability (Ismail et al., 2012; Lin \& Chen, 2008). There is limited knowledge of the role of how the integrated shared knowledge and the organizational capability contributing to the organization's strategic planning and objectives (Lin \& Chen, 2008). Also, the existing literature has not addressed the role of shared knowledge, and the organizational capabilities impact the role of NPD and innovation capabilities. Many researchers discussed the gap that determined the factors affecting and impacting NPD and innovative capabilities (Ismail et al., 2012; Lin \& Chen, 2008, 2008). As a result, further investigation is needed to explore how shared knowledge and the organization's capabilities affect NPD and innovative capabilities regarding their contribution to the firm's success, performance, and sustainability. The study aims to examine how the integrated shared knowledge and organizational capabilities impact NPD and innovative capabilities, contribute to the firms' success, and whether they lead to competitive product advantage.

Accordingly, this research addresses the gaps above by exploring how integrated shared knowledge and the organization's capabilities influence managerial innovation-decision and strategic planning. The research also explores how integrated shared knowledge and organizational capabilities contribute to the firm's success, performance, and sustainability. Also, it explores the connection between the integrated shared knowledge and the organization's capabilities and the firm's NPD and innovation capabilities. Besides, this study contributes by presenting the important role and the connection of integrated shared knowledge and the organization's capabilities to NPD and innovative capabilities. Also, this study addresses how shared knowledge and organization affect management and the firm's goals and plans.

\section{Theoretical/Conceptual Framework}

The essence of this multi-case study consisted of a qualitative methodology with an embedded, multi-case study. The methodology in this multi-site case study guided the researcher to obtain the necessary data and knowledge that benefits the participants, the innovative organizations, business practitioners, and researchers. Researchers select the methodology based on the 
problem or opportunity to investigate, the purpose of the study, the theory base, or the data's nature (Roberts, 2010). This study adhered to the methodological rigor of qualitative, multisite case study design from Yin (2014) and Cooper and Schindler (2014).

This multi-site case study focuses on exploring how shared knowledge and the organization's capabilities affect NPD and innovative capabilities regarding their contribution to the firm's success, performance, and sustainability. This multi-site case study's theoretical foundation was guided by the following theories: knowledge management, innovation, new product development, the resource-based view of the firm, and organizational learning. An in-depth understanding of the data was required to support the theoretical framework of this multi-site case study. The researcher's responsibility is to demonstrate what makes this multi-case study a credible and interesting research study that has potential theoretical value (Alvesson \& Karreman, 2011).

The research's importance is seen in the outcome, which academics may use, researchers, and practitioners to develop a comprehensive understanding of how shared knowledge and organizational capabilities contribute to the firm's success, performance, and sustainability. The findings may link shared knowledge and organizational capabilities to NPD and innovative capabilities. The study's significance is to fill a gap in the existing literature regarding the role and the contribution of the shared knowledge and the organizational capabilities to the firm's success, performance, and sustainability. The research has been undertaken to develop a thorough understanding of the role and the connection between the shared knowledge and organizational capabilities and NPD's success and innovative capabilities. The results of this research also provide a better understanding of the role and impact of the integrated shared knowledge and the organizational capabilities on the firm's success, performance, sustainability, and innovative management strategic planning and goals.

The study's theoretical framework was an outcome of the following three theoretical gaps and reasons in the innovation literature.

1. There is limited knowledge on the impact and the contribution of the integrated shared knowledge and the organizational capabilities to the firm's success, performance, and sustainability

2. The current literature did not address the role and the impact of the integrated shared knowledge and the organization's capabilities on NPD and innovation capabilities and their contribution to the firm's success, performance, and sustainability

3. The existing literature has failed to address the influence of shared knowledge and the organization's capabilities on managerial innovation-decision and strategic planning related to NPD and innovative capabilities. Also, the role of shared knowledge that affects NPD and the firm's innovative capabilities had never been examined.

\section{Methodology of the Study}

\subsection{Design}

Due to the nature of the study, the research design for this study was a qualitative multi-site 
case study. This multi-site case study aimed to answer the research question and achieve its purpose by studying a small, qualified participant sample, allowing the researcher to understand the organizations through the focus on the participants' perspectives regarding this phenomenon (Stake, 2006). The case study method is appropriate for answering how and what questions. The setting and context of the data collected should be considered to appropriately answer the research question (Yin, 2015). According to Marshall and Rossman (2016), "one of the strengths of the case study approach is the methodological eclecticism; a variety of methods may be used" (p. 19).

\subsection{Exploratory Research Aim}

An exploratory qualitative multi-site case study was selected as it was appropriate for this research, using various data sources to gain in-depth knowledge and a better understanding of the phenomenon within its context. The selection of a qualitative multi-site case study was based on the researchers' interest in reviewing individual cases (Hyett et al., 2014). The purpose of this multi-site case study was to examine how shared knowledge and the organization's capabilities contribute to the firm's success, performance, and sustainability. This multi-site case study aimed to explore the link between shared knowledge and organizational capabilities and NPD and innovation capabilities. The researcher in this multi-site case study focused on the participants' perspectives and the subjective reviews that can only be obtained by a qualitative method. The study was structured on Eisenhardt's (1989) process of planning, selecting cases, applying overlapping data, shaping hypotheses through tabulation of evidence, comparing and constructing findings within the literature, and offering new conceptual frameworks when themes saturation has been reached. This structure allowed an iterative approach to research planning, design, preparation, data collection, analysis, and reporting each case in detail.

Throughout the interview with the selected participants, the participants were asked to define NPD, innovation capability, and the leading factors that affect NPD and innovative capability, including offering a brief explanation of why each factor was selected. To develop a better understanding of their perceptions, they were asked to describe the role and the impact of shared knowledge and the organization's capabilities regarding the contribution to the firm's success, performance, and sustainability. Interview data were triangulated with each organization's quality, operations, innovative applications, innovation capabilities, objectives, vision, and other relevant documents such as strategic plans, annual reports, or internal communications.

\subsection{Assumptions}

Assumptions are the beliefs or conditions, which are unproven or unconscious on the researcher's part and include ideas and premises, which the researcher takes for granted (Roberts, 2010). Qualitative research contains assumptions and limitations at various stages of the research study. Leedy and Ormond (2014) asserted that while assumptions lack supporting evidence, the research would be pointless if the assumptions themselves did not exist. Assumptions are the milestone that the study builds on (Leedy \& Ormond). Delimitations are characteristics of a research study related to the researcher's decisions to include or exclude 


\section{Macrothink MInstitute}

elements in the research design that impact the study's scope (Osieja, 2016). Limitations are factors that might affect the study's purpose, which is out of the researcher's control. Identifications of the study's limitations demonstrate the researcher's awareness of the inherent weakness of the selected methodology (Roberts, 2010).

The research is based on a qualitative approach and a multi-site case study design, leading the researcher to adopt a constructive worldview. The researcher chose to do a multi-case study analysis to review in-depth detail with each participant the factors influencing NPD and innovative capabilities. Constructivists may possess the following assumptions: (a) humans being constructed meanings as they engage with the world they are interpreting, (b) humans engage with their world and make sense of it bases on their historical and social perspectives, and (c) the basic generations of meaning is always social, arising in and out of interactions with a human community (Creswell, 2014). The researcher identified and considered the following assumptions, delimitations, and limitations of the research study.

In this study, a multi-site case is selected to review in-depth detail with each participant the factors influencing NPD and innovative capabilities and their contribution to the firms' competitive advantage, strategic management development, and achieving the firm's objectives. This multi-site case study was conducted to explore how shared knowledge and organizational capability affect the NPD and innovative capability regarding their contribution to the firm's success, performance, and sustainability. Also, this study explored the link between shared knowledge and organizational capabilities and innovative capabilities and NPD. This exploratory multi-site case study was conducted based on the following assumptions. First, the research occurs in natural settings, where human behavior and the event occur. Second, the researcher is the primary instrument in data collection, where the researcher relies on the participants' perceptions and experience. Third, the population selected was experts, executive team members, and professionals of NPD and innovative organizations that the Charlestonian community has recognized.

Since this study's purpose was the exploration, identification, and development of new and emergent themes and patterns, the sample of organization-participants selected did not threaten the validity of this multi-site case study. Instead, the diverse perceptions of the selected organization-participants generated information that advanced the body of knowledge on innovation management, NPD, and innovative capability by understanding the role of shared knowledge and the organizational capability as factors that affect the NPD and innovation capability within the innovative organizations. Fourth, the population was experts, executive team members, business owners, and professionals of NPD and innovative organizations in the Charlestonian market that have been recognized by the community based on several factors, including innovation performances, innovation practices, and innovation capabilities, and for their success in innovation filed. The innovative companies whose core business is directly related to NPD and implementing innovative capabilities recognized by the Charlestonian community were the sampling frame for this study.

The population sample's inclusion requirements include individuals who were directly involved in innovative practices and NPD projects or studies for at least seven (7) years and with significant operational and administrative authority. The selected organizations varied in 
operations, number of employees, field, and core competence. The selected participants have been involved in innovative practices and NPD for at least seven (7) years and with significant operational and administrative authority. Open-ended interview questions were posed to participants to support the exploration and examination of this study. The fifth assumption of this multi-site case study revolved around the presumption of the connection between shared knowledge and organizational capability as factors that affect the NPD and innovative capability. This study's sixth assumption was based on how shared knowledge and organizational capabilities link to the firm's NPD and innovation capabilities. Seventh, the collected data are descriptive and are interpreted regarding the particulars of a case rather than generalizations. The final assumption, the researcher seeks believability based on coherence, insight, and instrumental utility, and trustworthiness through a process of verification rather than through traditional validity and reliability measures.

\subsection{Delimitations}

The identified population is a delimitation of the study. The delimitations of the research study begun from selecting the companies and the innovative organizations only from one county located in Texas, ending by the data collection process, and types which included: observation of the participants and the organizations' documents, the interviews, the documents that were provided, and the audio-recorder that was used in the interviews. The study was limited only to innovative organizations located in Texas that were selected based on their reputation, core business, implementation of innovation and NPD, and community recognition. The study was not limited to a specific industry, sector, or size of an organization.

The research method consisted of a qualitative multi-site case study interviewing executive team members, experts, and professionals of NPD and innovative organizations from each of the selected sites for this study. Face-to-face interviews were applied to establish a personal connection, enhance qualitative data's richness, and pay attention to detail. Significant insight into considering the multi-site case study is that it allows resembling multiple experiments and following a replication logic design that enables the researcher to explore differences within and between cases. The researcher did not gather data from professionals outside of Texas. The results of the study reflect data from a limited subset of the population. Therefore, the data does not reflect how global organizations approach implementation how shared knowledge and the organization's capabilities contribute to the firm's success, performance, and sustainability.

\subsection{Limitations}

The limitations of this study were related to the participants and the researcher. The sampling frame for this study and the population sample's inclusion requirements was a boundary limitation of this study. The researcher did not have control over which the various applications and implementation of NPD and organizational capabilities. The researcher's lack of experience conducting interviews was a limitation of this study. The researcher's inexperience could have inadvertently introduced participants' bias if the researcher did not insert enough objectivity into the interview process itself.

\subsection{Target Population and Sample}


Qualitative researchers may categorize the respondent pool as the sample, but sampling technique definitions infer statistical analysis of representing the entire population in the universe (Yin, 2014). This multi-site case study design did not obtain respondents through sampling. It applied Yin's (2014) concept of analytic generalization, which contends that respondents are purposefully selected to shed empirical light on theoretical and principles. This multi-site case study aimed to answer the research question and achieve its purpose by studying a small, qualified participant sample, allowing the researcher to gain a stronger understanding of the organizations (Stake, 2006). This multi-site case study's target population was experts, executive team members, business owners, and professionals of NPD and innovative organizations in the Texas market recognized by the community based on several factors, including innovative performances, innovative practices, and innovative capabilities. The innovative companies, whose core business is directly related to NPD and the implementation of innovative capabilities recognized by the Charlestonian community, were the sampling frame for this study.

\subsection{Population}

This multi-site case study's target population was experts, executive team members, business owners, and professionals of NPD and innovative organizations in the Texas market. The population sample's inclusion requirements include individuals who were currently employed and directly involved in innovation practices and NPD projects or studies. The participants must have obtained at least a bachelor's degree with at least seven (7) years with significant operational and administrative authority. The selected organizations varied in operations, number of employees, field, and core competence.

\subsection{Sample}

This study's sample consisted of executive team members and experts from each of the selected sites for this study. The recruitment sample size was 15 innovative organizations in the Charlestonian market from various specializations. From the sample size of 11, the researcher was able to conduct six (6) interviews representing six (6) innovative Charlestonian companies with qualified participants. Characteristics of the ideal sample included both the project manager expert/executive team member of new product development project teams that utilize NPD and innovation capabilities. The researcher interviewed qualified participants to collect different perspectives and conduct a deep and detailed study regarding this phenomenon. Purposive sampling selection is derived based on Patton's (2015) and Yin's (2014) recommendations. Patton stated that "purposive sampling emphasizes an in-depth understanding and learning a great deal about the inquiry issue" (p.137). Yin stated that "purposive sampling ensures that the participants will have the experience, information, and knowledge to answer the research question" (p. 87).

\subsection{Qualitative Data Collection}

\subsubsection{Data Collection}

The researcher prepared a list of 12 companies was selected from Texas for this study. The researcher reached 15 innovative organizations and interviewed six (6) qualified participants 
from those organizations. The number of selected organizations was based on the purpose and the intent of the study (Cleary et al., 2014). The appropriate sample for this study has resulted in sufficient saturation of the participants' interviews for the research (Eisenhardt \& Graebner, 2007; Stake, 2006). Stake $(1995,2006)$ recommended that researchers conducting a qualitative study should have a sample size that would enable the researcher to answer the research questions.

Contact information for the selected innovative organizations was obtained through the websites of each identified organization. The researcher contacted the identified site representative via phone to describe the study and sampling frame, to request contact information, and to ask for their organization's support and participation in this study to conduct research on-site. The researcher visited each organization's site after gaining approval and their support to participate. Then, the researcher spoke with each organization's gatekeeper to provide more details of the study and answer any questions or concerns. The researcher requested the contact information for the individuals that met the research's requirements and qualifications from the appropriate organization representative based on the inclusion criteria.

This study's primary collection method instrument was the in-depth, intensive, semi-structured interview using open-ended questions. Interviews provided a well-organized method for gathering a great deal of detailed, empirical data, particularly in unique or complex scenarios (Eisenhardt \& Graebner, 2007; Patton, 2015). Each of the participants was interviewed individually based on a previously prepared list in a place that had private accommodations and was mutually acceptable to both the participant and the interviewer. A set of open-ended questions was designed to collect and obtain data to clarify and better understand the topic or the phenomenon (Yin, 2014). Open-ended questions allowed respondents to answer in detail, clarify responses, and get close and special attention to the interviewee's view and perspective about their experiences and related meaning (Yin, 2014). Depending on the participants' answers, probing was used as needed to provide a deeper understanding of the shared perspective, issue, or topic. Probing questions were ideal for the researcher to clarify the respondent's perspective and help the researcher think critically and analytically.

This study acquired data from primary decision-makers of the most recognized innovative businesses and providers in Texas. A limitation was present in the collection of information from the primary decision-makers of the larger businesses. The researcher captured information about respondents about NPD and innovative capabilities roles, and the impact of shared knowledge and the organization's capabilities, with at least seven years of experience and power that may influence business innovation or strategic agility or operations organization. The participants were assured that all the information provided, their organization identity, and the personal perspectives and views would remain confidential. Considering the researcher and participant's lack of interaction in this type of interview, it becomes crucial for the researcher to build rapport with the participant (Trier-Bieniek, 2012). That was achieved by creating small talk before the interview began to better identify with one another (Trier-Bieniek, 2012). With all the confidentiality assurance, one (1) out of the 8 participants refused to record the interview; they just allowed the researcher to take notes while conducting the interview and viewing the organization documents. Each interview was recorded by a voice recording device with a high 


\section{Macrothink $\Lambda$ Institute}

level of filtration to reduce noise, miss-hearing, or interruption and to ensure that the interview was recorded clearly with high quality.

\subsubsection{Data Analysis}

The researcher's analysis includes direct quotations from the participant interviews. The quotations were used as the basis in support of the researcher's analysis. The qualifying data obtained through the interview was prepared and reviewed for eligibility by the researcher. This multi-site case study combined traditional and contemporary data analysis practices. Traditional techniques cannot entirely replicate qualitative data analysis software features, and the traditional techniques must be applied before and after the use of the qualitative data analytics software (Yin, 2014). The combination of traditional and contemporary strategies delivered increased dependability, credibility, validity, and reliability.

Once the researcher completed the initial analysis, NVivo 11 was used to perform a similar analysis type. NVivo was the suggested qualitative data analytics software for the multi-site case study, serving as the central software tool. The function of NVivo was to convert unstructured data to structured data through the process of coding. NVivo 11 was used to manage and analyze the data. NVivo 11 was utilized further to uncover themes, frequencies, and similarities. Furthermore, the results of both the researcher and NVivo 11 were then compared to build further upon the findings.

\subsubsection{Instruments}

The obtained data through a one-on-one interview was recorded, transcribed, and analyzed by the researcher and by NVivo 11 . The NVivo 11 program was used as the primary tool for organizing, managing, and analyzing the data. Bazeley and Jackson (2013) recommend using NVivo to guide the research's data collection and analysis. Literature, memos, and annotations were used to initiate the project in NVivo to create a foundation for organizing the data as it was collected and verifying conclusions drawn from the analysis. Interview transcriptions, organizational documents, and sources of evidence collected and considered were added to the NVivo project. The data collected were transcribed before the use of NVivo 11. The researcher had to get absorbed and engaged with the data to understand the phenomena being explored and then developed a coding system to employ within the software (Noble \& Smith, 2014). The researcher's analysis was performed before the NVivo 11 analysis to validate any results that may surface from the software. By running the NVivo 11 analysis after the researcher has conducted the initial analysis, any possible bias was removed that may be encountered if the software analysis was run first.

Seers (2012) recommended reviewing the transcripts paragraph by paragraph to determine the coding process to not become overwhelmed with the data. Franzosi, Doyle, Mcclelland, Putnam Rankin, and Vicari (2013) recommended using code families to reduce the number of codes produced by NVivo 11 and to simplify the data. Generating word clouds from the platform elevated visualization of the data and were applied to increase readability. Coding plans began with the research questions and the interview questions, and the codes were not conclusive until after data collection (Swanson \& Holton, 2005). NVivo 11 was used to uncover themes, frequencies, and similarities that the researcher was unable to determine. Furthermore, 
the results of both the researcher and NVivo 11 are then compared to build further upon the findings.

The findings produced in NVivo 11 were far more advanced than that of the researcher. There were many similarities in the overall determination that the researcher made. Anyan (2013) mentioned that a researcher could interpret the data on how they best feel will answer the research question; therefore, using another form of analysis to support the findings of the researcher will contribute to the validity of the study. According to Jirwe (2011), NVivo 11 is also considered advantageous since it allows the researcher to identify consistency and inconsistency in their data analysis.

\section{Results}

It was determined that the integrated shared knowledge and the organization's capabilities have a critical effect and positive impact on the Charlestonian innovative team members, the innovative managerial planning, and strategies, and contribute to the firms' success, performance, and sustainability. The study emphasizes the importance of the firm's use of shared knowledge and the organization's capabilities effectively by the NPD and team members. This multi-site case study focused on gathering information and data from qualified participants within the field on NPD and innovative capability about the role of the shared knowledge and the organization's capabilities regarding their contribution to the firm's success, performance, and sustainability. It was discovered through this study that the integrated shared knowledge and the organization's capabilities are interconnected, significantly affect NPD and innovative capabilities, and contribute to the firm's success and performance.

Also, other factors affecting the NPD and the innovative capabilities of an innovative firm that the participants shared were addressed. Project and innovative managers can now use one or more of these factors to support more effective NPD and innovative practices. The research findings add value to managers and leaders, minimize the risk and uncertainty, and develop foresight for the changes and practices that impact NPD and innovative capability. Consequently, the results of the exploratory multi-site case study can add new knowledge and principles to innovative management and competitive advantage theory through the increase in awareness and research of connecting and involving the role and the contribution of the integrated shared knowledge and the organization's capabilities to the firm's success, performance, and sustainability. The results and findings of this study are significant to the field of innovation management because it aims to better understand the factors that impact the success of NPD and innovative capability and consider new factors that are deemed essential for innovative firms. The findings can aid organizations with strategic planning and decisionmaking of NPD and innovative capability and contribute to the firm's success, performance, and sustainability.

\section{Discussion}

The researcher's determination supported that participants felt that shared knowledge and the organization's capabilities were needed by the NPD teams towards success and achieving the firms' innovative objectives. They also expressed the essential, critical, and vital role of the shared knowledge and the organization's capabilities with innovative management to stay 
competitive and improve and enhance the product development process. Furthermore, in support of the central research question, the researcher determined that shared knowledge and the organization's capabilities have an extreme connection to the firm's success, performance, competitiveness, and sustainability. The researcher was also able to affirm that shared knowledge and organizational capabilities have a critical impact on the firm's success, performance, building, or improving the competitive advantage. This effect can be proven and seen in any innovative firm, especially for NPD team members.

NVivo 11 was utilized to validate and find any other meaning within the data. NVivo 11 has found that the five determined topics' word frequencies were in line with the researcher's handcoding. The NVivo 11 analysis pointed out the impact and the contribution of the shared knowledge and the organization's capabilities, and the effect on the innovative management strategic planning and practices. The identified themes affirmed a more positive attitude toward NPD and innovative capability after the shared knowledge and the organization's capabilities were implemented. The researcher and the results from NVivo determined that shared knowledge and the organization's capabilities are significantly connected and supportive of NPD's success and innovative capabilities. The results also determined that shared knowledge and the organization's capabilities contribute to the firm's success, performance, and sustainability. The contribution is seen by achieving the organization's objectives, sustaining the competitive advantage, and improving the firm's performance, which is also done by increasing and enhancing the NPD and the innovative capabilities rates and processes.

\section{Conclusions Based on the Results}

This study began to better understand the role of shared knowledge and the organization's capabilities that impact NPD and innovative capability. Also, it was designed to explore how shared knowledge and the organization's capabilities contribute to the firm's success, performance, and sustainability. The researcher designed this study to focus on the participant's perspectives and opinions in innovation and strategic management, particularly NPD and innovative capability, within manufacturing and innovative organizations that currently utilize shared knowledge and organizational capability.

The researcher and the NVivo analysis results show that shared knowledge and the organization's capabilities are significantly connected and supportive to the success of NPD and innovative capabilities and contribute to the firm's success, performance, and sustainability. The results also indicate that the team members of NPD shared knowledge enables the firm to improve or increase innovative capabilities, new product competitive advantage and add values to the products based on the market's and consumers' desires. It was determined that there had been an improvement in the firm's performance and competitiveness when implementing shared knowledge and the organization's capabilities through the firm's innovative activities and practices. Individuals who have had experience with NPD and innovative capability affirmed that their perception and experience of shared knowledge and the organization's capabilities had been positive and critical to NPD and innovative management.

The results indicated that shared knowledge, as an extension to the knowledge in a firm, is an array of actions that help the team members attain the desired project objectives and achieve 


\section{Macrothink $\Lambda$ Institute}

the firm's goals. Shared knowledge offers many benefits to the firms by increasing and improving the firm's performance, sustaining the competitive advantage, and maintaining the market share and the team members by increasing the level of collaboration and cooperation through the entire organization. The benefits of shared knowledge integration include empowering the exchange of knowledge, facilitating learning, promoting the organization's strategies, and enhancing the employees' competencies and the organization's capabilities to achieve individual and organization goals, assisting in reconfiguring the available resources, and maintaining competition in the market. Shared knowledge appears as a social process and contributes to the firm's success, performance, and sustaining a competitive advantage. It is proven based on the data analysis that the effectiveness of NPD and the firm's innovative capabilities depend on the integration of information and knowledge within the organization and a suitable combination of organizations' resources. The results also indicated that organizational competence essential for the NPD and innovative capabilities success are to be aware of what it knows and to have the ability to refigure the resources, recombine the knowledge and apply what it knows when it is needed to provide the firm the leverage to be more adaptive and proactive. More importantly, by taking advantage of knowledge sharing by utilizing sharing knowledge and exploiting knowledge sharing, NPD and innovative capacity can improve the performance, increase the success rate, reduce the risk factors, and develop a superior product that aims to add value. When utilized in conjunction with the firm's organizational capabilities, shared knowledge is one of the best practices that significantly impact NPD and innovative capabilities success.

It was determined that firms require internal resources and capabilities to absorb, assimilate, and reconfigure externally obtained knowledge for innovative firms to succeed in the implementation of NPD and innovation capabilities. Innovative companies must develop skills in coordinating the firm's resources and utilizing them most productively and efficiently. The results affirmed that the company's capabilities are the product of its organizational structure, strategic planning, management support, processes, practices, control, and monitoring systems. Innovative firms need to develop and revamp "strategic flexibility" to ensure NPD and innovative capabilities success. Strategic flexibility as a strategic capability enables the firm to be more proactive and adapt to the changes and challenges in the global markets and business environments. The benefits of developing strategic flexibility include creating new skills, opportunities and delivering new products successfully through the effective utilization of the firm's resources and knowledge.

The findings show that organizational capabilities are another important NPD performance measure and contribution to sustaining the firm's competitive advantage. Organizational capabilities build and integrate competencies across processes and activities, ultimately lead to product innovation, and maintain the competitive edge. Organizational capabilities seek to effectively utilize the firm's resources and increase organizational learning by building and sharing knowledge through the firm's processes and activities. NPD is viewed by the researcher and from the data analysis as an ongoing process that requires integration and collaboration with all departments, not to mention knowledge from various areas to achieve the firm's 
objectives and ensure success. The results show that having a knowledge base and being familiar with the organizational capabilities of the firm enables innovation and NPD managers to identify which agile capabilities are needed and what best practices and strategies are essential to cope with the dynamic environment and provide the firms with the ability to become adaptive and proactive. NPD's success depends on the managers' ability to utilize the available resources and the knowledge in developing new products, developing the strategic planning and decision, and integrating the firm's capabilities in operations, which collectively contributes to the firms' performance and maintaining the competitive advantage.

The success of NPD and innovative capabilities range from embracing the concept of knowledge management and to instilling the extension of knowledge management's notion and practices into the firm's structure, training, and processes, which provide the firm the leverage to sustain its competitive advantage and to maintain the market share. Developing a knowledge base accessible to the employees will facilitate sharing knowledge, disseminating experience, know-how, and learning between the team members and other departments. More telling, the success of NPD and innovative capabilities require sharing information, and this is associated with effective and efficient strategic planning, program development and decision making, organizations' goals, and NPD performance, where all contribute to the firm's success, performance, and the sustainability of the competitive advantage.

The study aimed to fill the gap in the existing literature that addresses NPD's success and the implementation of innovative capability by developing a comprehensive understanding of the critical role of shared knowledge and the organization's capabilities to the firm's sustainable competitive advantage. Organizations may benefit from this study by learning about the leading factors that contribute to NPD success and innovative capability regarding contributing to the firm's success, performance, and sustainability. This study's results are critical to the field of innovation management because they provided a better understanding of the factors that impact and contribute to the success of NPD and innovative capability. The results are designated to help innovative organizations ignored or limited knowledge of their impact on the firm's performance. The exploration of this multi-site case study assists innovative organizations with strategic planning and decisions. Increasing awareness was one of the purposes of this multicase study of these factors, which may provide organizations with knowledge and foundation to consider in the strategic decision-making process and planning. The findings help academics and practitioners better understand the role, impact, and contribution of the integrated shared knowledge and the organizational capabilities to the firm's success, performance, and competitive sustainability.

The findings benefit both scholars and practitioners. The scholars can use the findings to develop new practices concerning NPD and innovative capability to support the firm's sustainable competitive advantage. The findings also contribute to managers and leaders of NPD and innovative capability, considering shared knowledge and the organization's capabilities as vital and essential to its ability to develop new products and promote innovative capability. All of this contributes to developing or improving a long-term sustainable strategic competitive advantage. These multi-site case study results are beneficial for innovative managers in making the appropriate strategic decisions concerning NPD and innovative 
capabilities that lead to attaining strategic goals. The findings revealed interesting insights demonstrating how utilizing knowledge sharing and the organization's capabilities are linked and significantly related to NPD and innovative capability success. The results also indicated that shared knowledge enables the firm to improve and increase innovative capabilities with new product competitive advantage and performance. More importantly, shared knowledge and the organization's capabilities were deemed critical factors for the NPD project's success and the implementation of the firm's innovative capability. This result implies a connection between knowledge sharing and the organization's capabilities, and the firm's success, performance, and sustainability.

This research study also has addressed other factors shared by the participants, which need further study to determine their impact on the firm's NPD and innovative capabilities. Besides, the participants' shared insights also exposed some of the strategies adopted by Texas's innovative organizations and other proactive actions that were used to cope with the challenges that their organizations faced on the local and global levels. These adaptive strategies were adopted to cope with the political changes in the surrounding areas, the turmoil in the market, the high level of competitiveness, the evolution of trends and consumers' demands, and the rapid developments of technology and communications. The adopted strategies' main goal was to maintain their market share, address consumers' satisfaction, stay competitive, and sustain their competitive advantage.

\section{Recommendations for Future Research}

In light of the study's results and discussion, several recommendations and suggestions are presented. This qualitative multi-case study contributes to the existing body of research knowledge. There are some possible extensions to this study. Some are a result of the limitations discussed above, and others are concerned with the depth and breadth of the participants' shared perspectives. This study shows that the innovative organizations currently utilizing shared knowledge and the organization's capabilities have a better experience, performance, return, and expectations with the effectiveness of their NPD and innovative capability. Other sectors and industries, such as the service or hospitality industry, can be considered for future research. Future research can also consider other NPD dimensions, such as the degree of innovativeness, cost, etc. Fourth, future research can assess NPD performance through other NPD performance measures such as product and market measures. Fifth, recommendation involves research techniques. Future researchers can deploy additional qualitative research techniques, such as focus groups, interviews, in-context observations, simulated environment observations, or document review. Quantitative research studies could examine the statistical significance among NPD, innovation capabilities, knowledge management, performance, key performance indicator (KPI), product development success, consumers' relations and feedback, marketing, and business model innovation. Finally, future research can also examine the effect of external factors on NPD success, performance, and speed. Recommendations for further research have emerged from the primary data, limitations in the study design, and delimitations. The researcher recommends further investigation, both qualitative and quantitative, about a broader range of participants in the innovation industry.

The results of this exploratory qualitative multi-site case study support additional factors on 
NPD and innovative capability. The research findings filled the gaps in the existing literature by examining the role of shared knowledge and the organization's capabilities as critical factors that impact the firm's success, performance, and sustainability. The findings also increased the awareness and the knowledge and provided a better understanding of the role and the contribution of the shared knowledge and the organization's capabilities. The results also added new insights, perspectives, and other factors that impact the NPD and innovative capabilities. The findings determined how other factors influenced innovative management practices, strategic planning, and the decision-making process. The factors that may affect the NPD and the innovation capability were addressed and shared from the participants' perspectives. There are numerous potential opportunities for research in considering those factors. These factors, which need further investigation, are marketing, consumers' relations, and finance, and their relation to NPD, innovative capability, and innovative management. The researcher recommends future research questions based on those new factors. The following are the proposed future research questions generated from marketing, consumer relations, and finance.

- How does marketing affect and contribute to NPD, innovative capability, and innovative management?

- How do consumers' relations affect and contribute to NPD, innovative capability, and innovative management?

- How does finance affect and contribute to NPD, innovation capability, and innovation management?

- How can an innovative organization create and implement marketing, consumers relation, and finance to enable business innovation?

- How can organizational competencies be shared to enhance NPD and innovation capability?

The collected data could be expanded to include new product developments in other manufacturers or industries such as the biotechnology and pharmaceutical industries. The study's focus was on innovative companies whose core business was directly related to NPD and innovative capabilities in the Jordanian market. This expanded data would allow a more comprehensive analysis of new product development success, performance, and sustainability. In addition to the expansion of data to include other industries, the data could include failed products. These included products that did not complete the new product development process or experienced immediate market failure may allow greater discernment of the role of the affecting factors that contribute to the firm's success, performance, and sustainability.

Last but not least, the researcher believes that it would be beneficial to the expansion of this research study to understand the innovation management strategies, decision-making process, cultural differences, market characteristics, government regulations and laws, innovation agility, NPD, and innovative capability of firms in countries other than Jordan or the Middle 


\section{Macrothink M Institute}

East countries. Finally, new research questions are proposed. The research questions from this study may be segmented or repositioned.

\section{Conclusion}

In a nutshell, this multi-site case study concludes the research project on strategic management and innovation, practical NPD, and innovative capability. This study began to better understand the role of the shared knowledge and the organization's capabilities that impact NPD and the innovative capability regarding their contribution to the firm's success, performance, and sustainability. The researcher designed this study to focus on the participant's perspectives and opinions in innovation and strategic management, particularly NPD and innovative capability within organizations that currently utilize shared knowledge and the organization's capability.

Significantly, the purpose of the research was to explore how shared knowledge and the organization's capabilities, affecting NPD and innovation capabilities, contribute to the firm's success and performance and sustain the competitive advantage. The scholarly research focused on the impact of the integrated shared knowledge and organizational capabilities in innovative Jordanian organizations. Participants confirmed that business is being affected by the integrated shared knowledge and organizational capabilities and contributes to the firm's success, performance, and sustainability. This research aimed to increase awareness and comprehension of the role of shared knowledge of the organization's capabilities that contribute to the success of the NPD and innovative capabilities. Also, the focus was to address the link between the integrated shared knowledge and the organizational capabilities to the firm's success, performance, and sustainability.

More importantly, it was determined that there had been an improvement in the firm's performance and competitiveness when considering and implementing shared knowledge and the organization's capabilities through the firm's innovation activities and practices. Individuals who have had experience with NPD and innovative capability affirmed that their perception and experience of shared knowledge and the organization's capabilities had been positive and critical to NPD and innovative management. Data analysis, data results, findings, and recommendations from this study may be a desirable or suitable place to continue into the next phase of research for other researchers and this researcher alike.

\section{REFERENCES}

Alvarez, H., \& Iske, P. (2015). Internal capabilities and external knowledge sourcing for product innovation in LMT SMEs. Journal of Innovation Management, 3, 55-70. Retrieved from http://hdl.handle.net/10216/79104

Alvesson, M., \& Karreman, D. (2011). Qualitative research and theory development: mystery as a method. Thousand Oaks, CA: Sage.

Anders, P. N. (2006). Understanding dynamic capabilities through knowledge management. Journal of Knowledge Management, 10, 59-71. DOI:10.1108/13673270610679363

Anyan, F. (2013). The influence of power shifts in data collection and analysis stages: A focus on qualitative research interview. The Qualitative Report, 18(18), 1-9. http://tqr.nova.edu/ 


\section{Macrothink Institutem}

Awwad, A., \& Akroush, D. M. N. (2016). New product development performance success measures: exploratory research. EuroMed Journal of Business, 11, 2-29. DOI: 10.1108/emjb12-2014-0043

Badrinarayanan, V., \& Arnett, D. (2014). Effective virtual new product development teams: An integrated framework. IEEE Engineering Management Review, 40, 80-90. DOI:10.1109/emr.2012.6379403

Barclay, I., Dann, Z., \& Holroyd, P. (2000). Improving product development performance. New Product Development, 51-68. DOI:10.1016/b978-0-7506-4998-8.50008-6

Bazeley, P., \& Jackson, K. (2013). Qualitative data analysis with NVivo. Thousand Oaks, CA: Sage.

Brunswicker, S., \& Vanhaverbeke, W. (2014). Open innovation in small and medium-sized enterprises (SMEs): External knowledge sourcing strategies and internal organizational facilitators. Journal of Small Business Management, 53, 1241-1263. DOI:10.1111/jsbm.12120

Cheung, T. M. (2015). Continuity and change in China's strategic innovation system. Issues and Studies, 51, 139-169. DOI.org/10.1111/j.1460-2466.1994.tb00685.x

Cooper, R. G., \& Kleinschmidt, E. J. (2010). Success factors for new-product development. Wiley International Encyclopedia of Marketing. DOI:10.1002/9781444316568.wiem05021

Creswell, J. W. (2014). Research design: Qualitative, quantitative, and mixed methods approach (4th Ed.). Thousand Oaks, CA: Sage.

Dangol, R., \& Kos, A. (2014). Knightian uncertainty and risk. Journal of Strategy and Management, 7, 337-353. DOI:10.1108/JSMA-02-2014-0010

Eisenhardt, K. M. (1989). Building theories from case study research. The Academy of Management Review, 14, 532. DOI:10.2307/258557

Eisenhardt, K., \& Graebner, M. (2007). Theory building from cases: Opportunities and challenges. Academy of Management Journal, 50, 25-32. DOI:10.5465/amj.2007.24160888

Ernst, H. (2002). Success factors of new product development: A review of the empirical literature. International Journal of Management Reviews, 4(1), 1-40. DOI:10.1111/14682370.00075

Franzosi, R., Doyle, S., Mcclelland, L. E., Putnam Rankin, C., \& Vicari, S. (2013). Quantitative narrative analysis software options compared: PC-ACE and CAQDAS (ATLAS.ti, MAXqda, and NVivo). Quality and Quantity, 47, 3219-3247. DOI:10.1007/s11135-012-9714-3

Hong, P., Doll, W. J., Nahm, A. Y., \& Li, X. (2004). Knowledge sharing in integrated product development. European Journal of Innovation Management, 7, 102-112. DOI:10.1108/14601060410534393

Hussein, M. S. R., \& Mourad, M. (2014). The adoption of technological innovations in a B2B context: An empirical study on the higher education industry in Egypt. Journal of Business \& Industrial Marketing, 29, 525-545. DOI:10.1108/jbim-07-2013-0155 


\section{Macrothink M Institutem"}

Hyett, N., Kenny, A., \& Dickson-Swift, V. (2014). Methodology or method? A critical review of qualitative case study reports. International Journal of Qualitative Studies on Health and Well-being, 9. DOI:10.3402/qhw.v9.23606.

Ismail, M., \& Yusof, Z. (2010). The impact of individual factors on knowledge sharing quality. Journal of Organizational Knowledge Management, 2010, 1-13. DOI:10.5171/2010.327569

Jirwe, M. (2011). Analyzing qualitative data. Nurse Researcher, 18, 4-5. DOI:10.7748/nr2011.04.18.3.4.c8456

Kahn, K. B., Barczak, G., \& Moss, R. (2006). An exploratory investigation of NPD practices in nonprofit organizations. Journal of Product Innovation Management, 23, 512-527. DOI:10.1111/j.1540-5885.2006. 00221.x

Kahn, K. B., Barczak, G., \& Moss, R. (2012). Identifying new product development best practices. Business Horizons, 55, 293-305. DOI:10.1016/j.bushor.2012.01.006

Kalluri, V., \& Kodali, R. (2014). Analysis of new product development research: 1998-2009. Benchmarking: An International Journal, 21, 527-618. DOI:10.1108/bij-06-2012-0040

Kang, S., \& Kim, S. (2010). The integrative framework on knowledge management and new product development. Asian Journal on Quality, 11, 157-164. DOI: $10.1108 / 15982681011075961$

Lawson, B., \& Samson, D. (2001). Developing innovation capability in organizations: A dynamic capabilities approach. International Journal of Innovation Management, 5, 377-400. DOI:10.1142/s1363919601000427

Leedy, P., \& Ormrod, J. (2014). Practical research: Planning and design (11th ed). Boston, MA: Pearson Learning Solutions.

Li, X., Zheng, Y., \& Wang, C. L. (2016). Inter-firm collaboration in new product development in Chinese pharmaceutical companies. Asia Pacific Journal of Management, 33, 165-193. DOI:10.1007/s10490-015-9451-y

Liker, J. K., \& Morgan, J. (2011). Lean Product development as a system: A case study of the body and stamping development at Ford. Engineering Management Journal, 23, 16-28. DOI:10.1080/10429247.2011.11431884

Lilleoere, A.-M., \& Hansen, E. H. (2011). Knowledge-sharing practices in pharmaceutical research and development- a case study. Knowledge and Process Management, 18(3), 121-132. DOI:10.1002/kpm.379

Liu, Y., Wang, L., Yuan, C., \& Li, Y. (2012). Information communication, organizational capability, and new product development: An empirical study of Chinese firms. Journal of Technology Transfer, 37, 416-432. DOI:10.1007/s10961-010-9188-1

Malewicki, D., \& Sivakumar, K. (2004). Patents and product development strategies: A model of antecedents and consequences of patent value. European Journal of Innovation Management, 7, 5-22. DOI:10.1108/14601060410515600 
Marshall, C., \& Rossman, G. B. (2016). Designing qualitative research (6th ed.). Thousand Oaks, CA: Sage.

Moustaghfir, K., \& Schiuma, G. (2013). Knowledge, learning, and innovation: Research and perspectives. Journal of Knowledge Management, 17, 495-510. DOI:10.1108/JKM-04-20130141

Narkhede, B. E. (2017). Advance manufacturing strategy and firm performance. Benchmarking, an International Journal, 24, 62-101. DOI:10.1108/bij-05-2015-0053

Ngamkroeckjoti, C., Speece, M., \& Dimmitt, N. J. (2005). Environmental scanning in Thai food SMEs: The impact of technology strategy and technology turbulence. British Food Journal, 107(4), 285-305. DOI:10.1108/00070700510596884

Noble, H., \& Smith, J. (2014). Qualitative data analysis: a practical example. Evidence-Based Nursing, 17, 2-3. DOI:10.1136/eb-2013-101603

Osieja, H. (2016). Academic freedom: Foundations, limitations, and delimitations. Edulearn 16 Proceedings. DOI:10.21125/edulearn.2016.0393

Patton, M. Q. (2015). Qualitative research \& evaluation methods: Integrating theory and practice (4th ed.). Thousand Oaks, CA: Sage.

Phillips, F. Y. (2016). The circle of innovation. Journal of Innovation Management, 4, 12-31. DOI:10.1111/caim. v25.3

Roberts, C. (2010). The dissertation journey: A practical and comprehensive guide to planning, writing, and defending your dissertation (2nd Ed.). Thousand Oaks, CA: Corwin.

Saunila, M., \& Ukko, J. (2013). Facilitating innovation capability through performance measurement. Management Research Review, 36, 991-1010. DOI:10.1108/MRR-11-20110252

Schumpeter, J. Y. (2002). Schumpeter and the economic interpretation of history. Schumpeter and the Endogeneity of Technology. DOI:10.4324/9780203465356.ch1

Seers, K. (2012). Qualitative data analysis. Evidence-Based Nursing, 15, 2. DOI: 10.1136/ebnurs.2011.100352

Singh, L., \& Bhangoo, K. S. (2014). The state, systems of innovation and economic growth: Comparative perspectives from India and South Korea. Seoul Journal of Economics, 27, 4165. Retrieved from https://ssrn.com/abstract $=2424561$

Smithies, A. (n.d.). Schumpeter and Keynes. Schumpeter. DOI:10.4159/harvard.9780674367340.c25

Stake, E. R. (1995). The art of case studies research. Thousand Oaks, CA: Sage.

Stake, R. (2006). Multiple case study analysis. [Kindle Ed.]. New York, NY: The Guilford Press.

Swanson, R. A., \& Holton, E. F., III. (Eds.) (2005). Research in organizations: Foundations and methods of inquiry. San Francisco, CA: Berrett-Koehler. 
Teece, D. J., Pisano, G., \& Shuen, A. (1997). Dynamic capabilities and strategic management. Strategic Management Journal, 18, 509-33. DOI:10.1002/(sici)1097-0266(199708)18:7<509: aid-smj882>3.0.co;2-z

Teece, D. J., Pisano, G., \& Shuen, A. (2003). Dynamic capabilities and strategic management. Strategic Management Journal, 77-120. DOI:10.1142/9789812796929_0004

Trier-Bieniek, A. (2012). Framing the telephone interview as a participant-centered tool for qualitative research: a methodological discussion. Qualitative Research, 12(6), 630-644. DOI:10.1177/1468794112439005

Vinayak, K., \& Kodali, R. (2014). The relationship between NPD innovation and NPD performance: The moderating role of NPD best practices in the Indian manufacturing industry. Measuring Business Excellence, 18, 39 -59. DOI:10.1108/mbe-03-2013-0017

Xu, J., Houssin, R., Caillaud, E., \& Gardoni, M. (2010). The macro process of knowledge management for continuous innovation. Journal of Knowledge Management, 14, 573-591. DOI:10.1108/13673271011059536

Yang, J., \& Yu, L. (2012). Electronic new product development - a conceptual framework. Industrial Management \& Data Systems, 102, 218-225. DOI: 10.1108/02635570210423262

Yeşil, S., Koska, A., \& Büyükbeşe, T. (2013). Knowledge sharing process, innovation capability, and innovation performance: An empirical study. Procedia - Social and Behavioral Sciences, 217-225. DOI:10.1016/j.sbspro.2013.04.025

Yin, K. R. (2014). Case study research: Design and methods (5th ed.). Thousand Oaks, CA: Sage.

Yin, K. R. (2015). Qualitative research from start to finish (2nd ed.). Thousand Oaks, CA: Sage.

Zhang, Y. (2012). Research on evaluation of enterprise core competence based on grey system theory. Advances in Information Technology and Industry Applications, 119-126. DOI:10.1007/978-3-642-26001-8_16

Zhang, J., \& Zhu, M. (2015). Market orientation, product innovation and export performance: evidence from Chinese manufacturers. Journal of Strategic Marketing, 24, 377-397. DOI:10.1080/0965254x.20

\section{Copyright Disclaimer}

Copyright reserved by the author(s).

This article is an open-access article distributed under the terms and conditions of the Creative Commons Attribution license (http://creativecommons.org/licenses/by/3.0/). 